\title{
CAB - Collaboration across Borders: Peer Evaluation for Collaborative Learning
}

\author{
Janice Whatley and Frances Bell \\ University of Salford, UK \\ J.E.Whatley@salford.ac.uk \\ F.Bell@salford.ac.uk
}

Jan Shaylor
University College Chester, UK

J.Shaylor@chester.ac.uk

\section{Elena Zaitseva University of Salford, UK}

E.Zaitseva@salford.ac.uk

\author{
Danuta Zakrzewska, \\ Technical University Lodz, Poland
}

\author{
dzakrz@ics.p.lodz.pl
}

\begin{abstract}
Use of information and communication technologies (ICT) and the development of tools to enable communication, can change the ways in which students in higher education learn, including online learning, both as individuals and through collaboration with other learners. This paper is a review of two cases of online peer evaluation of web sites or multimedia presentations, between students from several countries. Examining the research feedback from these collaborative activities has contributed to our understanding of online learning tasks, and led to the development of a dedicated online portal for carrying out collaborative activities. We have found that there is a clear benefit to be derived from incorporating activities of this type within the learning of students in higher education. The CAB portal we have developed helps tutors, wishing to set up a collaborative activity, to address issues of reciprocity of learning outcomes and guidelines for students' participation.
\end{abstract}

Keywords: Collaborative and cooperative learning, online learning, dyadic exchange, computer mediated communication, virtual community.

\section{Introduction}

Although new technologies have the potential to change the ways in which students interact with their tutors and each other, the adoption of new technologies in higher education has been limited. For some academics transferring their teaching materials to digital format, such as documents and slide shows, and presenting them on a virtual learning environment (VLE) is a big step towards embracing the new technologies. Rapid progress in information and communication technologies

Material published as part of this journal, either on-line or in print, is copyrighted by Informing Science. Permission to make digital or paper copy of part or all of these works for personal or classroom use is granted without fee provided that the copies are not made or distributed for profit or commercial advantage AND that copies 1) bear this notice in full and 2) give the full citation on the first page. It is permissible to abstract these works so long as credit is given. To copy in all other cases or to republish or to post on a server or to redistribute to lists requires specific permission from the publisher at Publisher@InformingScience.org
(ICT) and in the development of tools to enable online communication, can change the ways in which students learn, including online learning, both as individuals and through collaboration with other learners. In this paper we review two cases of online peer evaluation of web sites and multime- 
dia presentations, as examples of collaborative activities, which have contributed to our understanding of online learning activities, and led to the development of a dedicated online portal for carrying out collaborative activities.

\section{Literature Review}

Collaborative learning has been widely researched and is now part of the $21^{\text {st }}$ century educational lexicon (Alavi \& Leidner, 2001). Collaborative and cooperative learning approaches are examples of social learning where learners communicate with the tutor and other learners as they undertake tasks or projects in which learning and cognition can be situated. Situations can be seen as co-producing knowledge through activity (Brown, Collins, \& Duguid, 1989), and where (as is usually the case) group activity occurs, dialogue and communication are important activities in this co-production. Vygotsky, a Russian educational psychologist who worked in the early $20^{\text {th }}$ century, recognised the social nature of learning. Vygotsky identified the Zone of Proximal Development (ZPD), where students can complete tasks, with the help of a teacher or more experienced peers that they would be unable to complete alone (Vygotsky, 1978). Group diversity in terms of knowledge and experience contributes positively to the learning process. The peer support system makes it possible for the learner to internalise both external knowledge and critical thinking skills and to convert them into tools for intellectual functioning (Gokhale, 1995).

Distinctions can be drawn between collaborative and cooperative learning approaches. Whilst both approaches involve learners working together to achieve an outcome, collaborative learning is a more student-centred approach where learners share in the creation of a joint solution, whereas cooperative learning involves processes whereby the task is divided into sub-tasks done by different learners(Curtis \& Lawson, 2001; Panitz, 1996). True collaborative learning requires significant interdependence between learners (Hung \& Chen, 2001) and relies on dialogue and other interactions between learners. Thus we can see that the degree of collaboration relies on the jointness and shared ownership of the outcome and the quality of interaction during the process.

Collaborative learning can take place through computer-mediated communication (CMC), offering a new context and increased opportunities (Curtis \& Lawson, 2001). Numerous studies show that computer-enabled collaborative activities can take place across all subject areas, offering a range of possibilities for improving students' academic performance (Kaye, 1992), foreign/ second language confidence (Biesenbach-Lucas, 2003),development of critical skills, reflection and the ability to explain and negotiate (Cogburn, 2003). Peer review and peer evaluation, as a form of collaboration, is recognised as a very important professional duty of future specialists and aimed at "... accepting and providing objective, critical, documented review of the work of others" (Alexander, 2000). Pedagogic benefits of this form of collaboration include increased student interaction with each other and with the learning materials, but evaluators and those whose work is evaluated might have different expectations of what benefit they can gain from engaging in the activity (de Abreu Moreira \& da Silva, 2003). Not only are those being evaluated exposing their work to critique, but as CMC is characterised by its reduced social cues, such as gesture, facial expression and body language, students may become frustrated by the lack of these (Hara \& Kling, 1999).

"The behaviors that characterize positive social interdependence include giving and receiving help, exchanging resources and information, giving and receiving feedback, challenging and encouraging each other, and jointly reflecting on progress and process. "(Curtis \& Lawson, 2001). This suggests a wide range of exchanges and associated behaviours that invite further research, to gain a rich understanding of the possibilities of collaboration within the context of peer evaluation. 
The concept of reciprocity and gift-giving has been studied in what are called virtual communities, i.e. communities of people whose interaction is wholly or partially mediated by ICT. Reciprocity, defined behaviour in which two people or groups of people help each other or exchange goods or services, operates variably in virtual communities. Reciprocity, or interdependence as Hung and Chen call it, may be exhibited as trust, or actual exchanges, e.g. of information (Hung $\&$ Chen, 2001; Miyata, 2002; Neice, 2002). Previous researchers have found that it is rarely dyadic, i.e. an exchange between two individuals, but more often following norms of generalized reciprocity where community members invest their support in the community for the benefit of others, with the expectation that they may themselves receive support at another time. This is characterised as 'social capital', which resolves the problems of collective action and binds communities together. Such a system of generalized exchange can be seen as operating within an ethos of mutual support (Alexander, 2000), or as a moral code that imposes a 'duty to repay' (Wang \& Fesenmaier, 2004). This sort of system operates over time and is associated with longer term communities and networks rather than short-term interactions, but obligations in short term activities may be resolved through formal record-keeping or through identity persistence where activities are repeated or prolonged (Wang \& Fesenmaier, 2004).

Goodyear's model of networked learning (Goodyear, 2001) was adopted for international online student collaborations between two or more groups of students in different organisational contexts, in a flexible model that requires only shared activity and sharing of the technical environment on which the visible CMC takes place, but permits different learning outcomes and related tasks, see Figure 1. This model was designed to accommodate international online collaborative activities for students that allow them to derive mutual benefit from the activity without major upheaval to their respective curricula. The student groups undertaking collaborative activities may not be studying the same subjects, but gain different and complementary benefits from an inter-disciplinary activity, in a reciprocal arrangement.

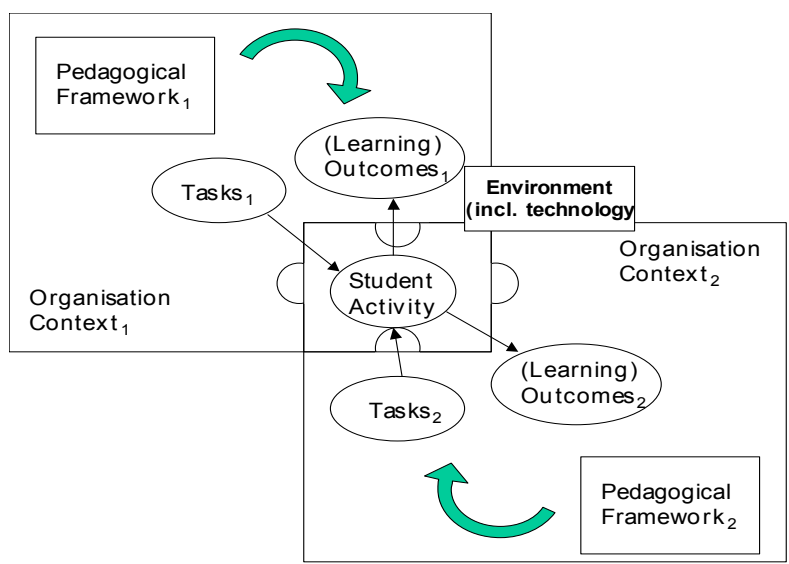

Figure 1 - Model for Collaboration Across Borders, adapted from Goodyear et al, 2001

The technologies used in collaborative learning (called the environment in Figure 1) may vary from simple e-mail exchanges, to more elaborate global interactions supported by complex, synchronous communication tools (Swigger, Alpaslan, Brazile, \& Monticino, 2004).

Early findings from the application of this model revealed the following:

- That benefits for each group should be available and clear to all concerned 
- That student motivation (sometimes increased by assessing the activity) affects participation

- That the relevance of the activity to the learning outcomes of the host module is important for each group involved

- That the planning of such activities is challenging given the differences in pedagogy and organisational arrangements (term dates, examinations, etc.)

- Language acquisition and the opportunities to learn about each other's cultures offer additional potential benefits.

Of course, implementing these findings is not easy, and richer understandings from specific cases will help those planning and conducting such student collaborations.

\section{The Collaboration across Borders Project}

Both cases studied in this paper took place in the first year of the two year project Collaboration Across Borders (CAB), funded under Socrates-Minerva. Six European higher education institutions initiated $\mathrm{CAB}$ to promote a particular type of online collaboration, whereby short-term collaborative activities take place between two or more student groups, using discussion forums and online chat. The objectives of the project that relate to the work in this paper are:

- To facilitate online collaboration between students and staff within this network, with an emphasis on critical evaluation and reflection

- To explore how emotions and language barriers impact upon online collaboration.

We have established a portal called CABWEB, using the Open Source software called Moodle, at http://moodle.cabweb.net. This portal hosts tutor and student networks, and collaboration spaces for student collaborative activities. Whilst tutors may see themselves as members of a persistent network, the students are getting together for a short-term activity whose goals, or learning outcomes, have been set by their tutor (see Figure 1). In this paper, we are using the concept of reciprocity to understand the nature of the collaborations in the context of peer evaluation activities. Within the setting of international student collaboration of at least two student cohorts, we aim to gain a rich understanding of the intended and actual exchanges and the behaviours that enable and constrain learning and student satisfaction. Critical evaluation is an important concept, but one that can raise negative emotions in those whose work is being criticised.

\section{Two Cases of Online Collaboration}

In this paper we describe two cases of collaboration, which took place in the spring of 2004. These demonstrate typical applications of activities where students can critically discuss the work of another set of students. These two cases are peer evaluation of web sites or multimedia presentation projects, in which the evaluating students were able to either offer help in particular design issues, or practice their language skills. Learning relies upon providing feedback to students so that they may reflect upon their achievements. In some cases tutors may design activities so that peers from the same institution evaluate the work of their students, but the feedback may not be objective, particularly if the evaluators are friends. In using feedback from students elsewhere, it is anticipated that the feedback will be more objective.

Where multimedia or web page projects are being developed as part of their learning, it is difficult to include sufficient time for the first attempts at prototypes to be modified in the light of feedback. In these two cases the feedback was acted upon in different ways: for the first case students were able to further develop their multimedia productions at a later date, whereas in the second case students prepared a report itemising the changes they would make to their web sites, if they were able to modify them. 
The students taking part in these activities were not working collaboratively or cooperatively as defined by Panitz, but are giving each other some form of benefit through an exchange of information or ideas. In these two cases most students were from computer science or information technology courses, but the inclusion of students from educational psychology and architecture gave an interdisciplinary focus on the activities. Table 1 summarises the two cases, showing the range of benefits each set of students received.

\begin{tabular}{|c|c|c|}
\hline \multicolumn{3}{|c|}{ Table 1 - Descriptions of two cases of collaboration } \\
\hline & Case 1 -Chester, UK (CHES) & Case 2 - Salford, UK (SAL) \\
\hline $\begin{array}{l}\text { Benefit to student project } \\
\text { developers }\end{array}$ & $\begin{array}{l}\text { Produced multimedia projects. } \\
\text { Evaluation to improve the us- } \\
\text { ability of the Chester students' } \\
\text { work, and to practice interna- } \\
\text { tional discussion. }\end{array}$ & $\begin{array}{l}\text { Produced prototype teaching } \\
\text { packages. Evaluation by students } \\
\text { from different subject areas: } \\
\text { pedagogical or computer sci- } \\
\text { ence/technical, to prepare a re- } \\
\text { port detailing possible improve- } \\
\text { ments. }\end{array}$ \\
\hline $\begin{array}{l}\text { Country of evaluating } \\
\text { students }\end{array}$ & \multicolumn{2}{|c|}{ Benefits to evaluating students } \\
\hline $\begin{array}{l}\text { Sydney, Australia (SYD). } \\
\text { Studying multimedia } \\
\text { within their architecture } \\
\text { programme of study. }\end{array}$ & $\begin{array}{l}\text { Practice evaluation of different } \\
\text { types of design (graphic, multi- } \\
\text { media, interface, narrative), im- } \\
\text { plemented in Director, and how } \\
\text { integration of media (images, } \\
\text { text, animation, sound and } \\
\text { video) was achieved. }\end{array}$ & - \\
\hline $\begin{array}{l}\text { Almere, Netherlands } \\
\text { (ALM). } \\
\text { Studying computer sci- } \\
\text { ence. }\end{array}$ & $\begin{array}{l}\text { Discuss development issues, } \\
\text { particularly relating to the inter- } \\
\text { face. }\end{array}$ & - \\
\hline $\begin{array}{l}\text { Murcia, Spain (MUR). } \\
\text { Studying educational } \\
\text { psychology. }\end{array}$ & $\begin{array}{l}\text { Applying theoretical knowledge } \\
\text { of psychology and learning theo- } \\
\text { ries to evaluation of the Chester } \\
\text { presentations, and practice writ- } \\
\text { ten English. }\end{array}$ & $\begin{array}{l}\text { Applying knowledge of educa- } \\
\text { tional psychology and learning } \\
\text { theories to evaluation of educa- } \\
\text { tional web-sites. Give feedback } \\
\text { on usability in general, relevance } \\
\text { of the content and age of in- } \\
\text { tended users. Practice written } \\
\text { discussion in English }\end{array}$ \\
\hline $\begin{array}{l}\text { Karlsruhe, Germany } \\
\text { (KAR). } \\
\text { Studying multimedia di- } \\
\text { dactics. }\end{array}$ & $\begin{array}{l}\text { After an introductory course of } \\
\text { learning theory, didactics and } \\
\text { multimedia learning, look at } \\
\text { concrete examples of multimedia } \\
\text { presentations, analyse their di- } \\
\text { dactical background and discuss } \\
\text { it with the authors. Practice writ- } \\
\text { ten discussion in English. }\end{array}$ & - \\
\hline $\begin{array}{l}\text { Lodz, Poland (LOD). } \\
\text { Studying computer sci- } \\
\text { ence. }\end{array}$ & - & $\begin{array}{l}\text { Discussing issues of project im- } \\
\text { plementation, use of different } \\
\text { technologies, and practice writ- } \\
\text { ten discussion in English. }\end{array}$ \\
\hline
\end{tabular}




\section{Case 1: Peer-evaluation of Multimedia Projects}

The first case study was a collaborative activity involving peer-evaluation of multi-media presentations. It was carried out with more then 100 students from five higher educational institutions: University College Chester (UK), Institute of Information Engineering, Almere (Netherlands), University of Karlsruhe (Germany), University of New South Wales (Sydney, Australia) and University of Murcia (Spain). The UK students were studying a multimedia module, and produced the multimedia presentations for evaluation. The evaluating students were able to offer help in multimedia, technical implementation, or usability issues.

The Dutch, German, Spanish and Australian students evaluated 32 multimedia projects, created by the final year students from University College Chester, over a period of two weeks. The outcome of the collaboration for the Chester students was to improve the usability of their projects, based on the feedback provided by the peer-evaluators. Discussion took place on forums provided by one of the institutions. The evaluating students were asked to look at the multimedia projects, and give feedback in accordance with criteria stipulated by their tutors, where possible initiating a discussion to provide sufficient details to enable the authors to make improvements. This they did either working individually or in groups. All students' performance in the collaboration was assessed by their tutor, either on the basis of their contribution to the discussion or on the quality of a final written report on the evaluation.

\section{Case 2: Peer-evaluation of Educational Web-site Prototypes}

The second case study was a peer-evaluation of prototypes of educational web sites, involving students from three universities: University of Salford (UK), Technical University of Lodz (Poland), and University of Murcia (Spain). Prototypes of interactive learning and teaching systems, made by the UK students, working in small groups, were made available online. The evaluating students were able to offer help on relevant learning theories and their practical implementation, or on technical issues. Collaboration took place over a period of six weeks, on a previously implemented CAB Forum, which was developed for testing purposes. The students were asked to provide feedback and initiate some discussion to elaborate on any feedback given. Students were either assessed by their tutors on a written report on the modifications they would recommend (evaluated students), or on their contribution to the discussion forum (evaluators).

\section{Data for Analysis}

All students were asked to fill in a post-collaboration on-line questionnaire and give their opinions about the effectiveness of the collaboration. Questions asked for feedback on communication difficulties, language and cultural issues, motivational and emotional background of collaboration and involvement in off-topic (social) interaction. Students also were asked to describe their most positive and negative experience gained from multi-cultural collaboration and give suggestions for improvements to such activities. The Polish students were asked to complete an additional questionnaire in the Polish language, so that the students were able to express themselves more clearly on their native language, whilst reflecting on the new educational experience, to provide feedback for the Polish tutors. Although there were no direct questions aimed at getting students' opinions of reciprocity in the collaborative activities, some of the questions were designed to reflect reciprocity issues indirectly.

In Case 1 , more than $50 \%$ of the students from every participated institution completed the questionnaire, and the students also participated in a focus group. In Case 2 the Polish and Spanish students gave their feedback using the questionnaire, but the Salford group only used a focus group to provide their opinions. 
Results of the post-collaborative questionnaire were used for descriptive statistics as well as qualitative analysis of students' responses. Data from the focus groups, which took place after the collaborative activity had finished, were exploited to obtain less formal feedback and to determine students' more personal feelings about the experience gained. The following section gives the research findings, relevant to our enquiries into perceived reciprocal benefits, and motivation to fully participate.

\section{Findings}

In an effort to ensure that students were aware of the benefits for each participating set of students, instructions for partner tutors and their students were sent out by the tutor for the students whose work was to be evaluated. The extent of the instructions and the manner in which they were distributed did vary, from postings of guidance on the web page, to printed instructions containing a set of criteria for evaluation. Students were asked to reflect on whether they thought the collaborative activity was an experience they benefited from. Figures 2 and 3 show the results from the questionnaire responses. Their motivation to participate may be affected by their perception of benefits to themselves and the collaborating students.

Overall most respondents agreed or were neutral to the benefits of collaboration, with only $19 \%$ disagreeing. The students who disagreed were the authors of the evaluated work, who may have had clear preconceptions of what they wanted to gain from the activity, and were more motivated to participate.

Benefits mentioned included gaining feedback on their work: "getting to know what people from around the world thought of my work", or an opportunity to give feedback and practice evalua-

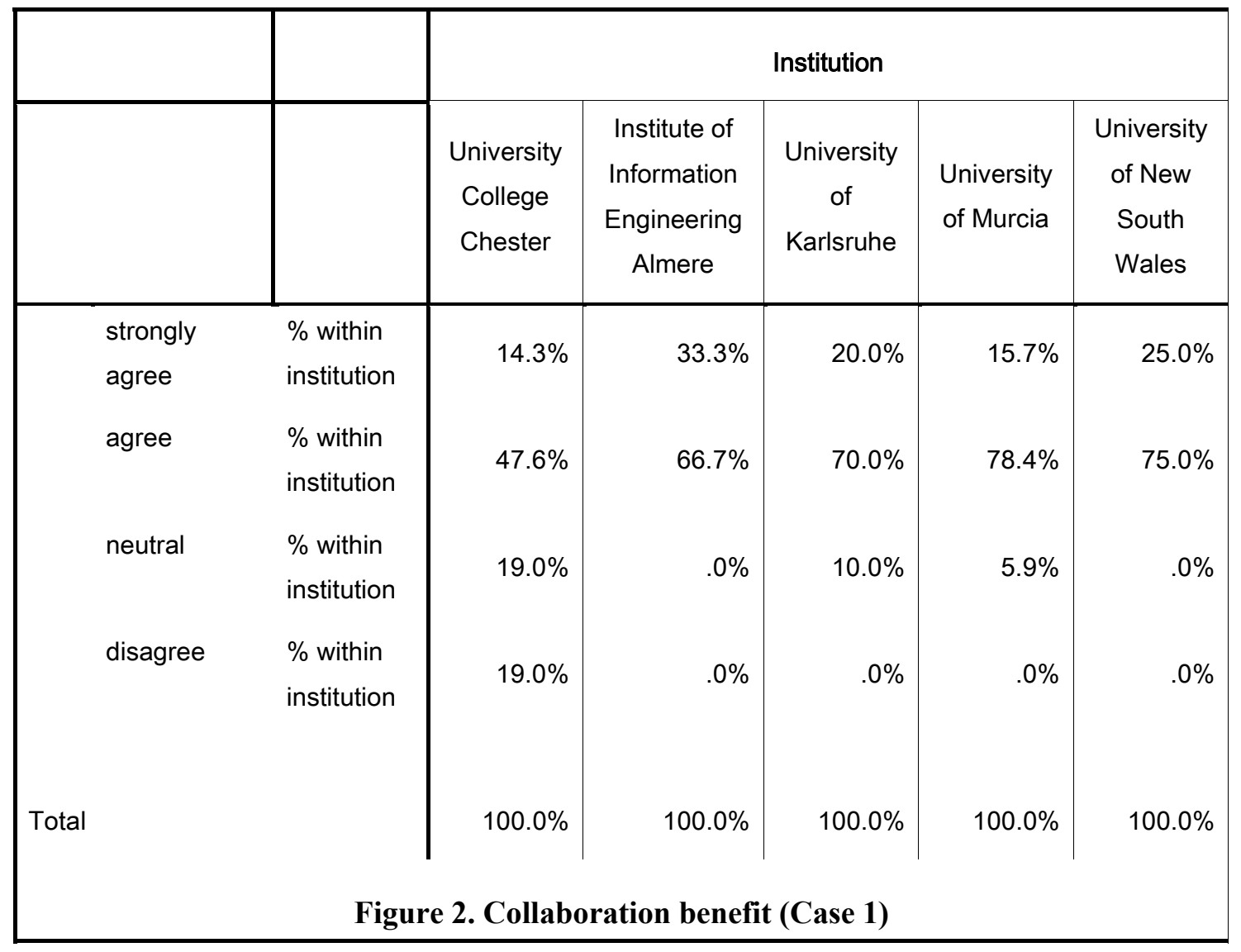




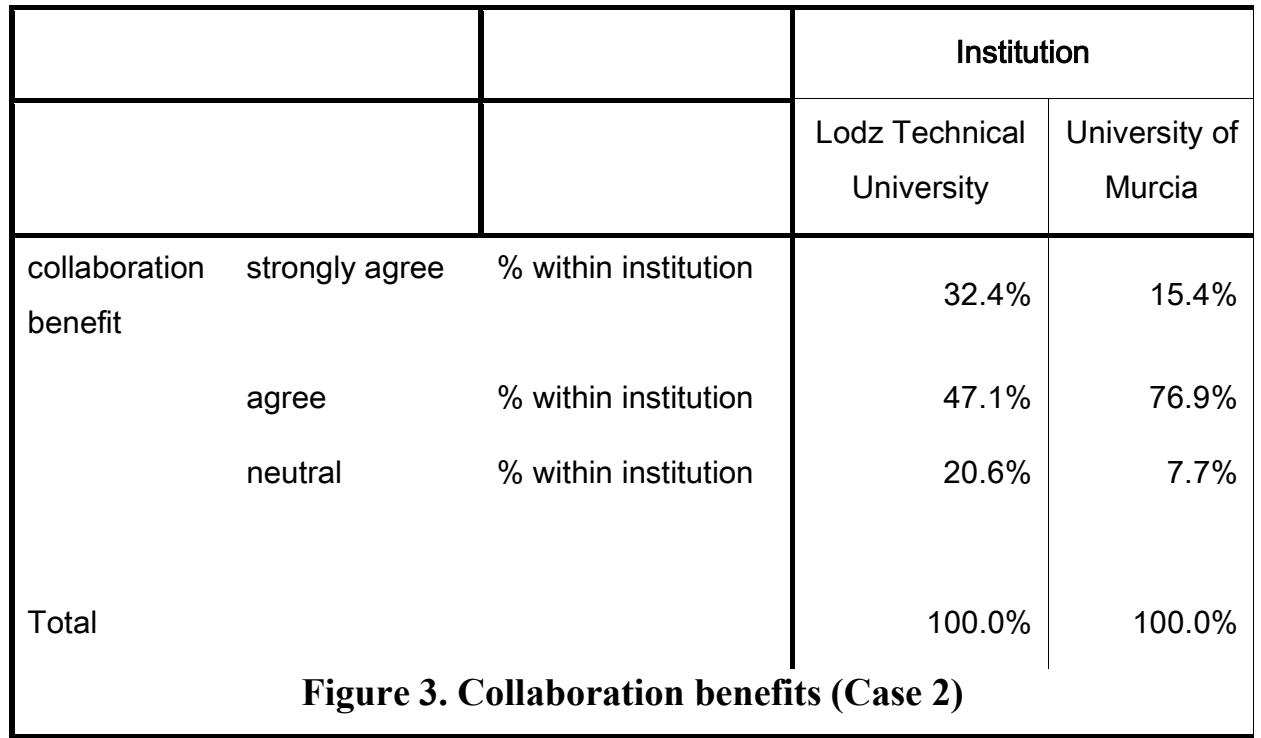

tion: "to have a very accurate look on the work of another student, to tell my thoughts and opinions as exactly as possible", showing an appreciation of reflection as part of their learning.

There was a perceived benefit through the exercise being international:

"finding out other peoples ideas and how different countries cultures affected the feedback", "I appreciated the honest suggestions put forward by the (foreign) students. Friends can be sometimes biased and reluctant to point out faults in the work". Another student said "... many thanks for your comments, your skills in design are very important as sometimes I think I miss things which is why any comments you make as a possible user are good...", also "Collaboration enables knowing abilities of students from abroad and comparing it with your own", and "Collaboration enables knowing other cultures and environments and broadening of horizons".

Many students, particularly evaluators also mentioned educational benefits from this collaboration, as well as their personal interest and enjoyment. Benefits and motivation to participate were obvious for at least three students groups (Sydney, Karlsruhe and Almere), who had been learning the same development tool, Macromedia Director, but in a different subject-oriented context to their counterparts.

Having received evaluations concentrating on missing parts of the context and graphics, some Salford students had to ask for more focused feedback to be able to complete their assignment:

"Could you give us some more detailed feedback about what needs improving. Think about it from the point of view of the user, a purchaser of the system or teacher/tutor using it for learning. Should the website by targeted a specific age group? What sort of features need adding? Should it be designed for use at school or at home? Please give as may suggestions as you can. The more the better, as long as they're realistic. Regards, Team C".

Some of the technical feedback was suggestions based upon the experience of the evaluators:

“.. OK, all of links (besides Storyboard \& Prototype) are opening *.doc page, WHY? i don't understann sence of this. Diagram would seen better in Scalable Vector Graphic format (svg)"

"... but I think that you should remember that people look at the side in different resolution so in $1024 \times 768$ is too small and the side is too empty."

"...I think that Flash objects are useless in this project, you can use simple java scripts to enlarge those icons on the bottom of the screen." 
We found an example of language support from a Salford student, who used online translation software to help some Spanish students who complained about difficulties with understanding English:

\section{"Hello students of Murcia University,}

I am sorry about the complicated language, I hope this has not been too much of a problem.

Please let us know if you have any specific comments about the website which might help us for future changes? We have tried to make the website look as professional as possible, please leave any comments. Your English is far better than my Spanish! Traducido usando los pescados de Babel - http://babelfish.altavista.com/babelfish/tr

Hola estudiantes de la universidad de Murcia,

Estoy apesadumbrado sobre la lengua complicada, yo espero que üste no ha sido demasiado de un problema. ïPor favor sepamos si usted tiene cualesquiera comentarios especuficos sobre el Web site que pudo ayudarnos para los cambios futuros? Hemos intentado hacer la mirada del Web site tan profesional como sea posible, deje por favor cualquier comentario. Y̆Su inglŭs es lejos mejor que mi espacol! Grazias.

P.S. Apesadumbrado para ninguna errores de la traducciyn, no soy muy bueno con espacol

On the other hand there was some criticism of the language skills of some participants:

“... The foreign students did not possess the language skills required to understand what our development was about"

Their motivation to participate may be affected by their perception of benefits to themselves and the collaborating students, but when asked whether they would wish to participate again in a similar exercise, there was a clear majority in favour (Figures 4 and 5).

Respondents recognised that this sort of collaboration could facilitate the exchange of ideas be-

\begin{tabular}{|c|c|c|c|c|c|c|}
\hline & & \multicolumn{5}{|c|}{ Institution } \\
\hline & & $\begin{array}{l}\text { University } \\
\text { College } \\
\text { Chester }\end{array}$ & $\begin{array}{l}\text { Institute of } \\
\text { Information } \\
\text { Engineering } \\
\text { Almere }\end{array}$ & $\begin{array}{l}\text { University of } \\
\text { Karlsruhe }\end{array}$ & $\begin{array}{l}\text { University } \\
\text { of Murcia }\end{array}$ & $\begin{array}{c}\text { University } \\
\text { of New } \\
\text { South } \\
\text { Wales }\end{array}$ \\
\hline yes & $\begin{array}{l}\% \text { within } \\
\text { institution }\end{array}$ & $47.6 \%$ & $83.3 \%$ & $60.0 \%$ & $60.0 \%$ & $62.5 \%$ \\
\hline no & $\begin{array}{l}\% \text { within } \\
\text { institution }\end{array}$ & $23.8 \%$ & $.0 \%$ & $10.0 \%$ & $11.1 \%$ & $.0 \%$ \\
\hline $\begin{array}{l}\text { not } \\
\text { sure }\end{array}$ & $\begin{array}{l}\% \text { within } \\
\text { institution }\end{array}$ & $28.6 \%$ & $16.7 \%$ & $30.0 \%$ & $28.9 \%$ & $37.5 \%$ \\
\hline Total & & $100.0 \%$ & $100.0 \%$ & $100.0 \%$ & $100.0 \%$ & $100.0 \%$ \\
\hline
\end{tabular}

Figure 4. Wish to participate again (Case 1) 


\begin{tabular}{|c|c|c|c|c|}
\hline & & & \multicolumn{2}{|c|}{ Institution } \\
\hline & & & $\begin{array}{l}\text { Lodz Tech- } \\
\text { nical Uni- } \\
\text { versity }\end{array}$ & $\begin{array}{c}\text { University of } \\
\text { Murcia }\end{array}$ \\
\hline \multirow[t]{3}{*}{$\begin{array}{l}\text { wish to partici- } \\
\text { pate once more }\end{array}$} & Yes & $\begin{array}{l}\% \text { within institu- } \\
\text { tion }\end{array}$ & $58.8 \%$ & $58.7 \%$ \\
\hline & No & $\begin{array}{l}\% \text { within institu- } \\
\text { tion }\end{array}$ & $20.6 \%$ & $10.9 \%$ \\
\hline & not sure & $\begin{array}{l}\% \text { within institu- } \\
\text { tion }\end{array}$ & $20.6 \%$ & $30.4 \%$ \\
\hline \multirow[t]{2}{*}{ Total } & & & $100.0 \%$ & $100.0 \%$ \\
\hline & \multicolumn{4}{|c|}{ Figure 5. Wish to participate again (Case 2) } \\
\hline
\end{tabular}

tween themselves and their counterparts. Among the best experiences of the collaboration, some Spanish students mentioned the following: "possibility to interact with the students abroad, making the project with the tecnoligi (technology), new experience, possibility to practice English". Polish students valued the "...possibility of communication, getting new ideas from other people, motivation to work facing new challenges".

There were some unexpected by-products of the activities, e.g. some German students said: “... Perhaps we will get some ideas for our own work, because next semester we have to do a work with macromedia also. Our english is not good. Please excuse it, and you are welcome to "elavuate" it!!!"

Case 2 was an evaluation of the work produced by students in teams of 4 or 5 , and necessarily involved discussion between the team members. However, it is interesting to find that the students from Case 1, who were having individual pieces of work evaluated, reported that the collaborative activity promoted some face to face discussion within their student groups. The survey revealed that overall two thirds of the respondents thought that the collaborative activity was actively discussed with their colleagues, see Figure 6 . Although the evaluated students were working individually, some of the evaluating students were working in small groups, and reported that the collaboration facilitated the exchange of ideas within their group.

\section{Discussion and Conclusions}

In each case, the stimulus for the collaborative activity was the need of one group to have their work evaluated. Other groups of students were enrolled to provide this evaluation and their benefits were established as complementary to the evaluation exercise that was the main focus of the collaborative activity. We can see in Figure 7 that the student group whose work was being evaluated appear at the hub of a wheel (Chester in Case 1 and Salford in Case 2), with relations between them and evaluating student groups forming the spokes of that wheel. Both cases were short-term collaborative activities organised by their tutors, and students had no persistent social capital, so, rather than a network of communication between student groups, we can see a set of dyadic relations between evaluated and evaluators. Along each spoke there is a clear exchange from the evaluator to the evaluated (shown as a solid line in Figure 7) that is well known to both 


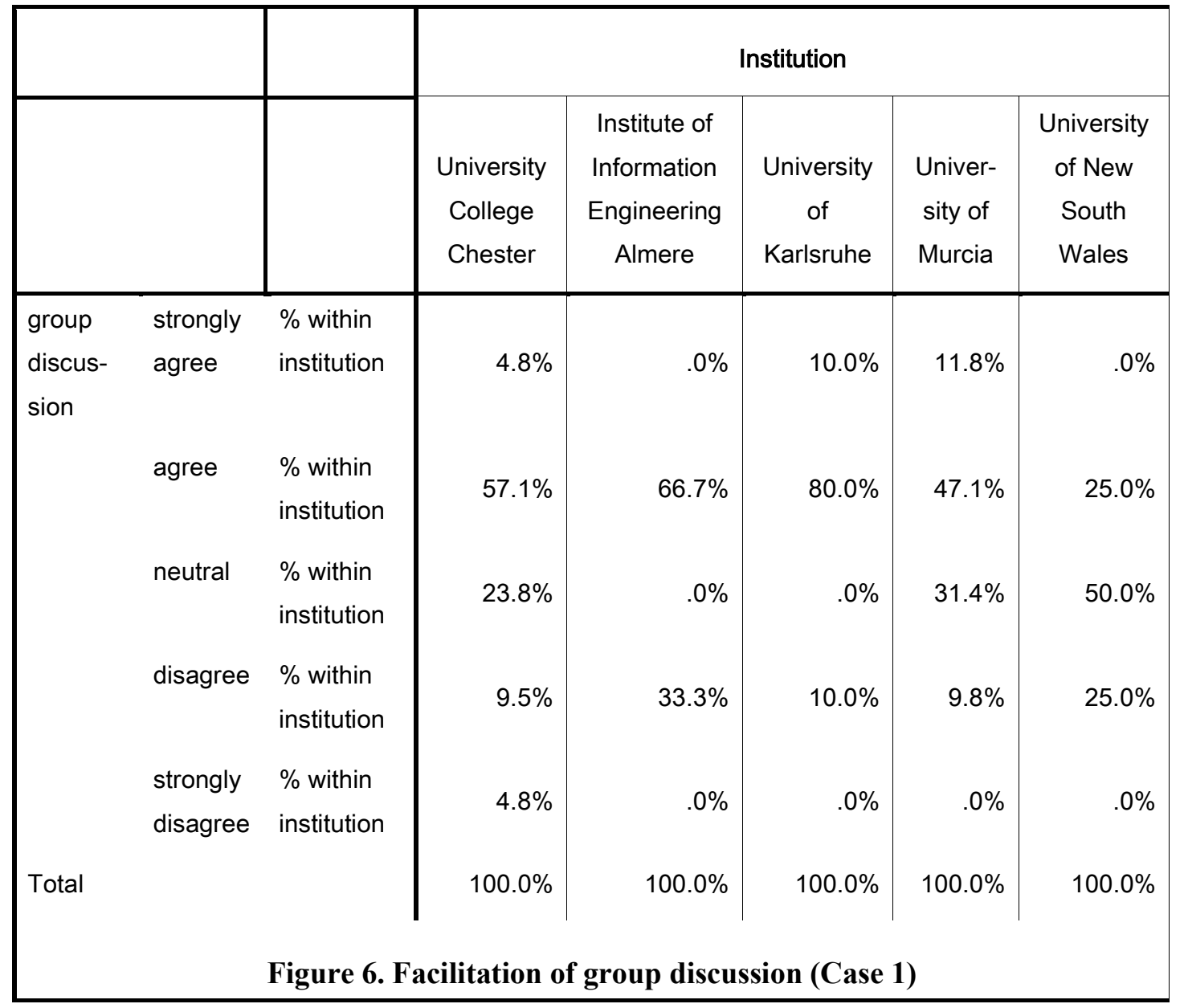

parties in the dyad (since it is the focus of the collaborative activity) and represents a strong need for the evaluated who needed this evaluation in time to complete their assessed task.

In contrast, the exchanges in the other directions, shown as dotted lines in Figure 7, are less strongly perceived as a timely need by the evaluators, and not obvious to the evaluated. If we look at what the evaluated are giving to the evaluators, it is an opportunity to practice their English, getting knowledge of another culture's artefacts, rehearsing their knowledge, or practicing evaluation, rather than a concrete exchange from evaluated to evaluators. In addition, the evaluated have to try to understand the various benefits available to their evaluators. There was encouraging evidence of the development of good will and 'social capital', as in several cases those students who had benefited from evaluations offered to 'return the favour', and help with evaluation of their peers' presentations in future.

By Panitz's and Curtis' definitions, these activities are cooperative rather than truly collaborative, since there is no joint solution that all students work towards. Using the concept of interdependence used by Hung and Curtis, we can see that in each of these collaborative activities, there is evidence of giving and receiving help and feedback, encouragement, and exchanging information but no evidence of joint reflection on progress. This is not surprising since there was no shared goal. The quality of the interaction relied on the goodwill of the students and their commitment to the true purpose of the activity, which was evaluation. 


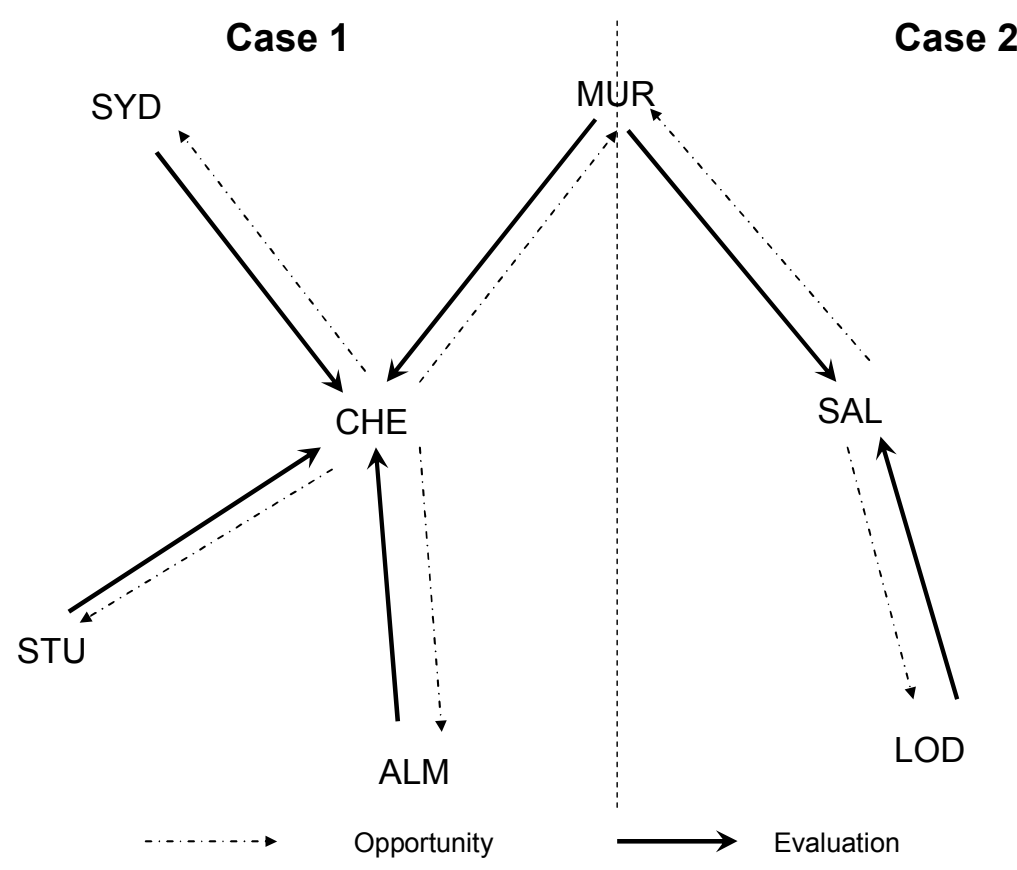

Figure 7 - Nature of Reciprocity in Cases 1 and 2

These activities were relatively complex from a group interaction perspective both for tutors organising them and students trying to understand what was happening. The information exchange about mutual benefits occurred mainly between tutors as a by-product of planning the activity rather than between student groups as an integral part of the activities themselves. Interestingly this served to emphasise the peer evaluation aspect (since this exchange was very clear to both parties in each dyadic relation). However the increase in complexity (e.g. timing and student availability) associated with the number of dyadic relations decreased the likelihood of student satisfaction in those with the stronger need, i.e. those whose work was being evaluated. Simultaneously these students were relatively unaware of the benefits that they could offer (in improving language, or discussion of technical implementation, exchange of ideas or human factors issues to other students in the set of dyadic relations.

On the other hand, unplanned benefits emerged from the collaborative activities. Some Chester students noticed the high level of academic English of the German students, causing them to reflect and try to improve on their own language and educational communication in English. Also the diversity of the groups (particularly in Case 1) offered the opportunity for students to experience multicultural communication, i.e. to compare communication styles, or to see evaluations done by students from different countries. 
We can conclude that improved understanding of what each group needs and when is likely to have an impact on student satisfaction and improve the likelihood of them achieving the pedagogic benefits planned by their tutors. Improved understanding could be achieved by requiring tutors (or students) to make known what they hope to gain and when, but this advice was given to tutors (all of whom are experienced and committed) prior to these cases. Having another student group dependent on them and waiting for their particular contribution should make both sides more responsible about their efforts and deadlines, and such accountability may be more powerful motivator to study. It seems that the problem may be the ownership of the main goal by one tutor and student group and the number of dyadic relations that a group must sustain in order to achieve that goal.

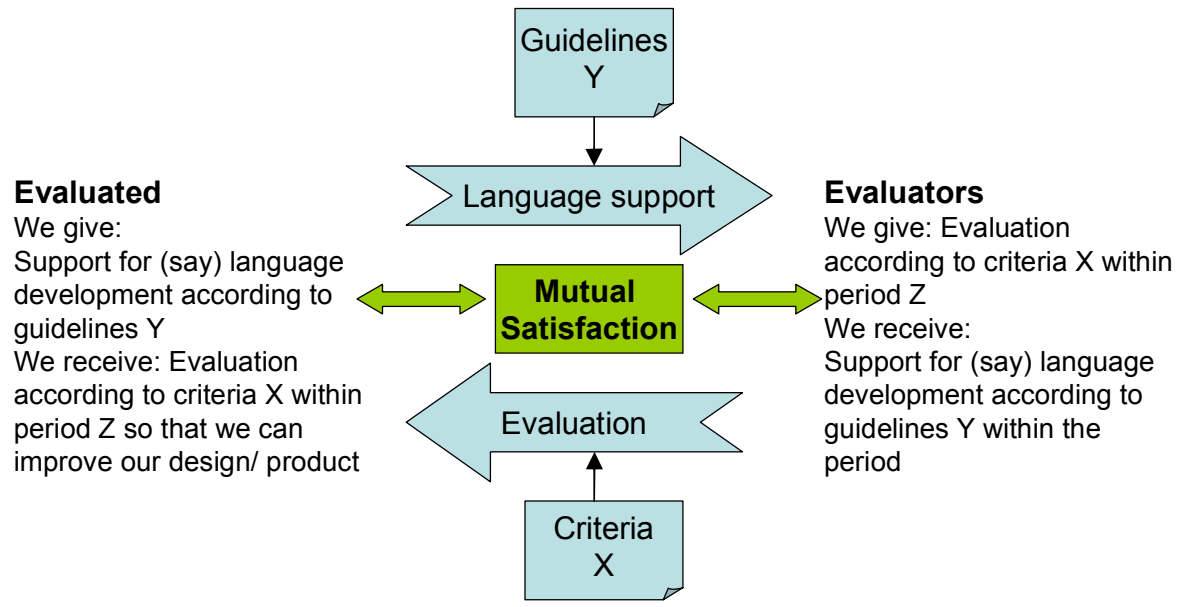

Figure 8 - Peer Evaluation as Dyadic Exchange

We recommend that this problem be alleviated by simplifying the dyadic relationship and by establishing a common goal, see Figure 8.

Many benefits could flow from having only one dyadic relation between evaluator and evaluated. The simplicity and equality of the relation could increase the negotiation of interests by each party so that the agreed exchange can be represented simply and understood by tutors and students alike. In the example shown in Figure 1, what each party gives and receives can be clearly articulated, and the "rules of engagement", including criteria, guidelines and dates, published and known to both parties. This two-way relation still applies to cooperative or exchange rather than collaborative learning but the simplicity and clarity will enhance the likelihood of mutual satisfaction and pedagogic benefit.

We have seen that the pursuance of a common goal will enable collaborative learning but within the constraints of a collaboration activity involving two groups of students, it is difficult to establish an activity with shared outcomes. However, if we make a shared outcome (in addition to the declared benefits that each group receives from the other) that students "own" the goal of mutual satisfaction, then it is possible for true collaboration to be achieved.

From examining the research findings of these two cases, we see that there is a clear benefit to be derived from incorporating activities of this type within the learning of students in higher education. The students involved were clearly willing to participate again in such activities, feeling that the benefit $\mathrm{s}$ outweighed any difficulties they encountered in the process. The findings from the two case studies in this paper have helped us to develop the CABWEB portal, in such a way that 
tutors are assisted in thinking about the exchanges, the learning outcomes and "rules of engagement" when designing the collaborative activity.

\section{Acknowledgements}

This project is supported by EU Minerva funding (Project Number is 110681-CP-1-2003-1-UKMINERVA-M ). We are grateful to the international team of tutors who made these collaborations possible: Frank Thissen, Cecilia Ruiz, Marcel Heerink, Jacqueline Hiemstra and Dean Utian.

\section{References}

Alavi, M., \& Leidner, D. E. (2001). Research commentary: Technology-mediated learning - A call for greater depth and breadth of research. Information Systems Research, 12 (1), 1-10.

Alexander, G. (2000). Information-based tools for building community and sustainability. Futures, 32 (34), 317-337.

Biesenbach-Lucas, S. (2003). Asynchronous discussion groups in teacher training classes: Perception of native and non-native students. Journal of Asynchronous Learning Networks, 7 (3).

Brown, J. S., Collins, A., \& Duguid, S. (1989). Situated cognition and the culture of learning. Educational Researcher, 18 (1), 32-42.

Cogburn, D. (2003). Globally-distributed collaborative learning and human capacity development in the knowledge economy. In D. Mulenga (Ed.), Globalisation and lifelong education: Critical perspectives. New Jersey: Lawrence Erlbaum.

Curtis, D. D., \& Lawson, M. J. (2001). Exploring collaborative online learning. Journal of Asynchronous Learning Network, 5 (1), 21-34.

de Abreu Moreira, D., \& da Silva, E. Q. (2003). A method to increase student interaction using student groups and peer review over the Internet. Education and Information Technologies, 8 (1), 47-54.

Gokhale, A. A. (1995). Collaborative learning enhances critical thinking. Journal of Technology in Education, 7 (1).

Goodyear, P. (2001). Effective networked learning in higher education: notes and guidelines. Centre for Studies in Advanced Learning Technology, Lancaster University.

Hara, N., \& Kling, R. (1999). Students' frustration with a web-base distance education course. First Monday, 4 (12).

Hung, D. W. L., \& Chen, D.-T. (2001). Situated cognition, Vygotskian thought and learning from the communities of practice perspective: Implications for the design of web-based e-learning. Education Media International, 38 (1), 3-12.

Kaye, A. R. (1992). Learning together apart. In A. R. Kaye (Ed.), Collaborative learning through computer conferencing (pp. 1-24). London: Springer-Verlag.

Miyata, K. (2002). Social support for Japanese mothers online and offline. In B. Wellman \& C. Haythornthwaite (Eds.), The Internet in everyday life (pp. 74-113): Blackwell Publishing.

Neice, D. C. (2002). Cyberspace and social distinctions: Two metaphors and a theory. In R. Mansell (Ed.), Inside the communication revolution: Evolving patterns of social and technical interaction (pp. 55-84). Oxford: Oxford University Press.

Panitz, T. (1996). A definition of collaborative vs. cooperative learning. Retrieved 15 September, 2000, from http://www.lgu.ac.uk/deliberations/collab.learning/panitz2.html

Swigger, K., Alpaslan, F., Brazile, R., \& Monticino, M. (2004). Effects of culture on computer-supported international collaborations. International Journal of Human-Computer Studies, 60 (3), 365-380. 
Vygotsky, L. S. (Ed.). (1978). Mind in society: The development of higher psychological processes. Cambridge, Mass.; London: Harvard University Press.

Wang, Y., \& Fesenmaier, D. R. (2004). Towards understanding members' general participation in and active contribution to an online travel community. Tourism Management, 25 (6), 709-722.

\section{Biographies}

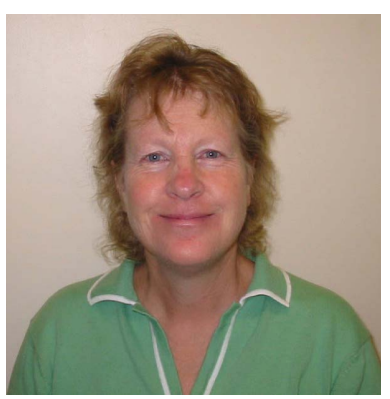

Janice Whatley is a lecturer in information systems development, elearning and multimedia, at the University of Salford, and author of several papers concerning online collaboration as a part of student learning. Current research interests include educational technology applications in Higher Education, in particular online collaboration and team working, also developing tools to support students undertaking team projects, helping them to develop their team working skills.

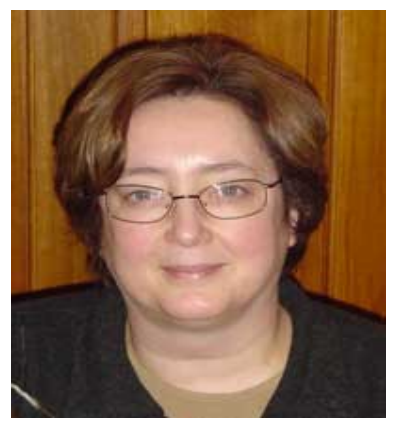

Frances Bell is a Senior Lecturer in the Information Systems Institute at the University of Salford. Her research interests include virtual organising and the use of information and communications technologies in teaching and learning. Frances is particularly interested in the bridge between information systems (IS) and educational research, specifically the use of IS (online communities) theories in educational research, and the use of educational research in organisation-based IS research She has published over 20 articles in conferences and journals, including International Journal of Web-based Communities, Education Media International, IFIP 8.2, UKAIS, ALT-C and EUNIS.

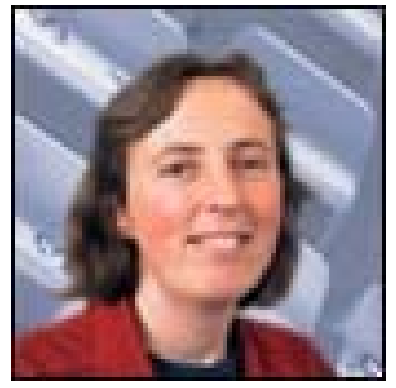

Jan Shaylor lectures in Multimedia Technology at University College Chester in England. She has wide experience of web-based learning techniques and collaborative learning and has presented papers at conferences both nationally and internationally. Current research involves effective online collaboration between HE students and staff based in different countries. 


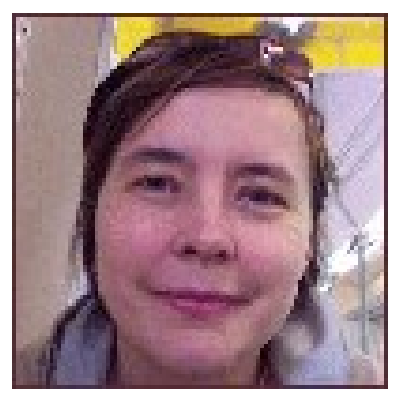

Dr Elena Zaitseva was involved in online teaching and learning in Russia and Japan for more then 15 years. Currently she is a research assistant for the $\mathrm{CAB}$ project with particular interest in intercultural aspects of computer mediated discussion. Her general research interests are around using collaborative learning environment for support of foreign language acquisition and cultural awareness.

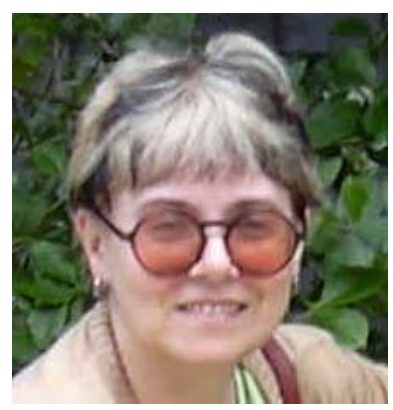

Dr Danuta Zakrzewska is the assistant professor at the Institute of Computer Science Technical University of Lodz. Her research interests focus in information management in organisations. In $\mathrm{CAB}$ project she is involved in investigation of language issues in student collaborations as well as sustainability of the project communities. 